\title{
Gangs and Culture: A Micro Review
}

\author{
Chandrika M Kelso* \\ School of Professional Studies, National University, USA
}

Submission: September 16, 2016; Published: October 21, 2016

*Corresponding author: Chandrika M Kelso, School of Professional Studies, National University, 11255 North Torrey Pines Road, La Jolla, CA 92037, USA

Abstract

Humans communicate verbally and non-verbally, employing the help of symbols, body language, or gestures. Communication involves symmetrical and complimentary transactions. Symmetrical and complimentary transactional thinking is when two individuals mirror each other's behaviors. The four dimensions of human communication are cultural (relies on the beliefs, values, and ways of behaving shared by a group of people), physical (tangible or concrete environment in which communication takes place), socio-psychological (includes status relationships amongst the participants), and temporal (includes the time and day as well as the time in history in which the communication occurs) [1-3]. Identity or the lack there of is an important aspect of the human life.

\section{Mini Review}

We use, develop, or adopt various strategies to either individualize ourselves or blend into the society we have chosen to be a part of, consciously or otherwise. Some set themselves apart from the others by the kind of clothing they wear, others may use certain colors to demarcate their identity or self, some may rely on a particular hair color, or style, body brandings, tattoos, or other physical, psychological, cultural mannerisms to create and craft their own identity, or modes of communication. Cultural mentality is the term used to describe the manner in which a society interprets reality. Each culture has its own unique aspects that may be misunderstood or misapprehended by those unfamiliar with them $[3,4]$. Whether street, prison or otherwise based, gangs have adopted this type of cultural mentality in the manner in which they conduct themselves.

The FBI estimates that 1.4 million gang members are criminally active in the U.S and Puerto Rico. Consequently, about 85 percent of serious gang activity is concentrated in metropolitan areas in the United States, and 16 percent of all homicides are credited to gangs. In cities with population of exceeding 100,000 the percentage of homicides increases to 25 (NGIC) [5]. According to US Department of Justice-Organized Crime \& Gang Section (US-DOJ-OCGS) [6], a gang is defined as an association of three or more individuals whose members collectively identify themselves by adopting a group identity which they use to create an atmosphere of fear or intimidation frequently by employing one or more of the following: a common name, slogan, identifying sign, symbol, tattoo or other physical marking, style or color of clothing, hairstyle, hand sign or graffiti; and the association's purpose, in part, is to engage in criminal activity and the association uses violence or intimidation to further its criminal objectives. Gang members engage in criminal activity, with the intent to enhance or preserve the association's power, reputation, or economic resources.

Gangs can be categorized based on their ethnic affiliation, their structure, or their membership. Gangs use unique hand signs and symbols, colors, clothing and tattoos, and other associated trade-marks to form a sense of identity within their individual groups. Though these identifiers may undergo revisions over time, the one constant seems to be the reliance on tattoos to establish gang identity. A gang like Crips prefers the color blue, while Bloods sport the color red; Crips also wear their hats to the right side, blue shoe laces in their right shoe, rolled up right pant leg, etc. Sureños use blue and white as their main identifiers [5,6]. Many cultures have and will continue to use tattoos as cultural symbols, so many gangs have incorporated tattoos into their primary identifiers. Some gangs use tattoos denoting the area code or state where the gang is located, others use tear drops or dots, each with a distinct meaning [6]. The most popular types of tattoos of gang members are the area code tattoos, teardrop tattoos, and dot tattoos. Each type of tattoo has special meaning to the gang. Area code tattoos are usually the area code or state where the gang is located, such as 817 (Fort Worth) or 213 (Los Angeles). 
Though originally known to denote the number of years served in prison, lately, tear drop tattoos have gained popularity with non-gang members as well. It has evolved to have multifaceted meaning to include remembering a deceased loved one. There are open and closed tear drops and also "half" tear drop which is only half filled in with ink to symbolize the fact that someone close to the wearer was killed and the wearer then killed the assailant. The dot tattoo meaning also varies from "Mi Vida Loca (my crazy life)" to the symbol of a gang known as Los Vatos Loco. If connected, the dots form a triangle, originally the three dots were associated with Hispanic gang members but no longer have such monopoly over it. Tattoo meanings sometimes vary with the region also. Some Latino gangs sport tattoos on their foreheads, a prominent display of their gang affiliation and loyalty. As another form of identifier and communication, gangs also use graffiti which may include the gang's name, a member's nickname, a declaration of loyalty, threats against rival gangs or a description of criminal acts in which the gang has been involved [7].

Everything in culture is learned, therefore, culture becomes a substitute for instinct as a way of responding to the environment. A subculture shares in the overall culture of the society but carriesits own distinctive values, norms, and life style, examples being the military or college campuses. But when a subculture is at odds with the dominant culture by proudly rejecting the important norms of a wider society, sociologists call is Counter culture. Strain and value conflict in society is generated by large counter cultures [8]. Gangs, therefore, fit the definition of a counterculture. They are detrimental to the growth, welfare or success of any society they inhabit, and must be eradicated with precision and effectiveness. However, just as terrorism presents many challenges, so do the gangs that infiltrate our society.

\section{References}

1. Bram J (1953) Culture: A critical review of concepts and definitions. American Sociological Review 18(4): 442-443 2p.

2. Devito JA (2003) Human communication. Pearson Education.

3. Chandrika M Kelso, Hugh D Kelso (2013) Crisis $\Lambda$ Vs. Crisis $\Omega$ : An explorative view. Journal of Management Policy and Practice 14(5).

4. Wahrman R and Denisoff S R (1975) An introduction to sociology. Macmillan Publishing Co, Inc, New York, USA.

5. National Gang Intelligence Center (NGIC) (2015) National Gang Report.

6. USDOJ-OCGS (2015) About violent gangs.

7. Al Valdez (2009) Gangs: A guide to Understanding Street gangs - $\left(5^{\text {th }}\right.$ edn.) Law Tech Publishing.

8. Robertson I (1981) Sociology. Worth Publishers, New York, USA.

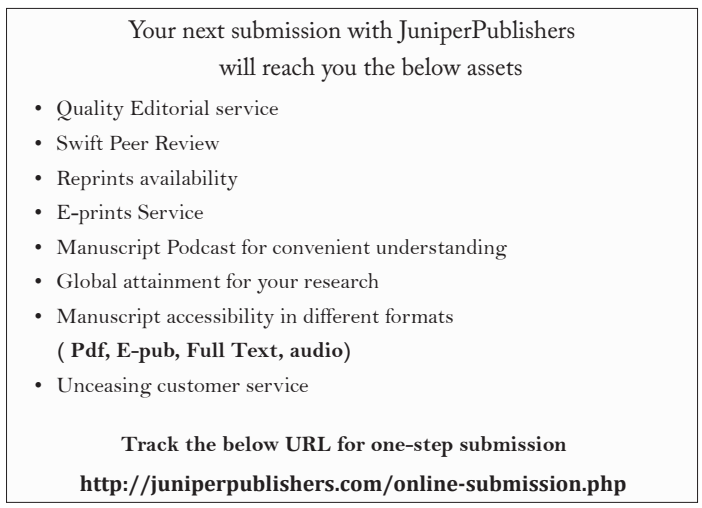

